\title{
Synthesis, characterization and theoretical study of the new aluminate ionic
}

\section{liquid: triphenylphosphonium trichloroiodoaluminate}

\author{
Shahriar Ghammamy* and Sadjad Sedaghat
}

Department of Chemistry, Islamic Azad University, Malard Branch, Malard, Iran

\begin{tabular}{l}
\hline A R T I C L E I N F O \\
\hline Article history: \\
Received May 30, 2012 \\
Received in Revised form \\
June 23, 2012 \\
Accepted 9 July2012 \\
Available online \\
9 July 2012 \\
\hline Keywords: \\
Aluminate \\
DFT \\
Frequency \\
Ionic liquid \\
Room temperature \\
\hline
\end{tabular}

\begin{abstract}
A B S T R A C T
The synthesis of Triphenylphosphonium trichloroiodoaluminate (III) ionic liquids (ILs) is reported here. The product was characterized by spectroscopic and analytical methods such as 31P-NMR, FT-IR, cyclic voltammetry, CHN, TGA and differential thermal analysis (DTA). Thermal analyses were used to investigate the thermal behavior of this compound. The results show that this ILs has excellent thermal stability below $110^{\circ} \mathrm{C}$. Along with the experimental study; this compound has been studied computationally at the B3LYP/LANL2DZ level of theory using the Gaussian 98 program package. From these calculations, optimized geometries, molecular parameters, and vibrational spectra of ILs have been calculated. In addition, calculated frequencies are compared with the experimental frequencies after correction by the appropriate scaling factor. This comparison shows that our theoretical data are in good agreement with the experimental results.
\end{abstract}

C 2012 Growing Science Ltd. All rights reserved.

\section{Introduction}

Transparent ceramics have recently attracted tremendous interest from researchers and there are literally many applications such as lasers and cutting tools, transparent armor windows, night vision devices (NVD) and nose cones for heat looking missiles. Presently, available infrared (IR) transparent materials show a trade-off between optical performance and mechanical strength. For instance, sapphire (crystalline alumina) is very strong, but it does not maintain full transparency throughout the 3-5 micrometer mid-IR range. Yttria is completely transparent from 3-5 micrometers, but it does not have sufficient strength, hardness, and thermal shock resistance for high-performance aerospace use. Therefore, a combination of these two materials in the form of the yttria-alumina garnet (YAG) has been used in the field, effectively. Recently, researchers have demonstrated that laser elements including amplifiers, switches, ion hosts, etc. made by fine-grained ceramic nanomaterials generated 
by the low temperature sintering of high purity nanoparticles and powders can be constructed, less expensively. These items are free of internal stress or intrinsic birefringence, and permit relatively large doping levels or optimized doping profiles.

At the end of twentieth century, scientists found that unlike traditional view about the melting points of salts, there is a class of salts or salt mixtures those have melting points below $115^{\circ} \mathrm{C}$, which are referred as ionic liquids ${ }^{1}$. Room-temperature ionic liquids (RTIL) ${ }^{2}$ are ionic liquids with melting points at or below room temperature ${ }^{3}$. Some ionic liquids (RTIL) are nonflammable, nonvolatile, or thermally stable and can be used as a promising replacement for the traditional organic solvents. Moreover, many workers have synthesized and studied about ionic liquids. The ionic liquids in organic reaction are often obtained as organic product in these reactions and these can be removed easily from the ionic liquid by extraction with organic solvent without resorting to an aqueous workup or solvent evaporation. It is noteworthy that ionic liquids have been applied for many other purposes. For example, during past years, ionic liquids have been applied to synthesize different compounds ${ }^{4}$, polymerization processes, dye synthesis, supercritical fluid chromatography, and determination of phenothiazine derivatives, preparation of sensors and biosensors, preparation of nanostructures, and other applications ${ }^{5}$.

However, recent reports indicated that several ionic liquids have been applied to separate various mixtures $^{6}$. Moreover, ionic liquid properties such as heat capacities and refractive index ${ }^{7}$, luminescence properties $^{8}$, osmotic coefficients ${ }^{9}$, enthalpy, density, heat capacity ${ }^{10}$, and thermophysical properties ${ }^{11}$ have been studied since their first synthesis. Therewith, following our previous studies on ionic liquids' chemistry ${ }^{12}$, we decided to improve our knowledge about these compounds by synthesis, characterization, and theoretical the study of a new aluminum-based ionic liquid. This is useful when a metal catalyst is used in the reaction that is this catalyst often remains in the ionic liquid and can be directly reused. In addition, ionic liquids as a class of novel environmental "green solvents," have remarkable new properties and promising applications in many fields. The first RTIL, ethyl ammonium nitrate $\left(\mathrm{mp} 13-14{ }^{\circ} \mathrm{C}\right)$, was reported in 1914 . However, ionic liquids did not draw much attention till 1992, when Wilkes and coworkers reported air- and water-stable RTILs based on imidazolium salts. Subsequently, research on their synthesis, properties, and applications has increased substantially. In this work, the synthesis, structural, bonding, thermal solubility, vibrational properties, and computational study of a new aluminate ILs have been reported. From the results, calculated molecular parameters and vibrational frequencies are shown.

\section{Experimental}

\subsection{Materials and Methods}

Starting materials were obtained from Merck and were used without further purification. Solvents were purified by standard methods. Organic solvents were reagent grade. Voltammogram was obtained in two different velocities by Metrohm 827. The IR spectrum was recorded using FTIR Bruker Tensor 27 spectrometer. All the chemical shifts are quoted in ppm using the high-frequency positive convention. The percent composition of elements was obtained from the Microanalytical Laboratories, Department of Chemistry, OIRC, Tehran.

\subsection{General procedure}

Triphenylphosphonium trichloroiodoaluminate (III) $\left[\mathrm{P}\left(\mathrm{C}_{6} \mathrm{H}_{5}\right)_{3} \mathrm{H}\right]^{+}\left[\mathrm{AlCl}_{3} \mathrm{I}\right]^{-}$, prepared by this method:

In a $100-\mathrm{mL}$ round-bottom flask, dry triphenylphosphine $(0.25 \mathrm{~g}, 0.953 \mathrm{mmol})$ was dissolved in dry acetonitrile $(20 \mathrm{~mL})$ and was stirred for $30 \mathrm{~min}$. While the mixture was stirred, HI $(0.12 \mathrm{~g}, 0.938$ mmol) was added to this mixture and stirring continued for 5 minutes. $\mathrm{AlCl}_{3}(0.12 \mathrm{~g}, 0.9 \mathrm{mmol})$ in 
acetonitrile was added to this mixture and stirring was continued for $4 \mathrm{~h}$ to precipitate a white solid. A white precipitate was filtered and washed with ether and hexane: M.P.: 105-106 ; Anal. Calc. for $\left[\mathrm{P}\left(\mathrm{C}_{6} \mathrm{H}_{5}\right)_{3} \mathrm{H}\right]^{+}\left[\mathrm{AlCl}_{3} \mathrm{I}\right]^{-}$: Calculated C, 51.003; H, 3.77. Found: C, 51.01; H, 3.95. IR ( $\left.\mathrm{KBr}\right)\left(\mathrm{cm}^{-1}\right)$ : 2400, 992, 1474, 1656, 3423, 1427, 539, 452, 719, $1116 \mathrm{~cm}^{-1} .{ }^{31} \mathrm{P} \mathrm{NMR}\left(135 \mathrm{MHz}, \mathrm{CDCl}_{3}\right): \delta=$ 26.106 ppm (Fig. 1, Fig. 2).

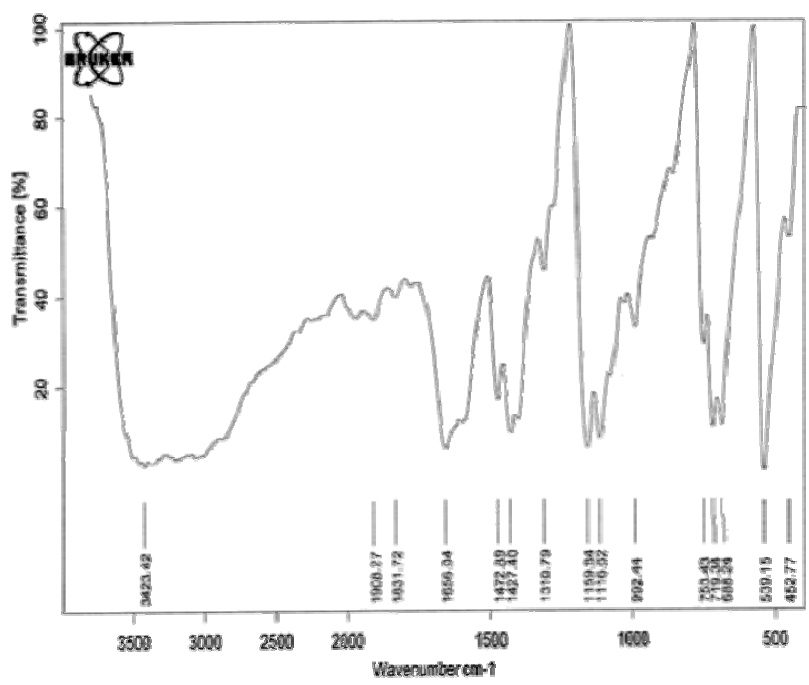

Fig. 1. IR spectrum of $\left[\mathrm{P}\left(\mathrm{C}_{6} \mathrm{H}_{5}\right)_{3} \mathrm{H}\right]^{+}\left[\mathrm{AlCl}_{3} \mathrm{I}\right]^{-}$

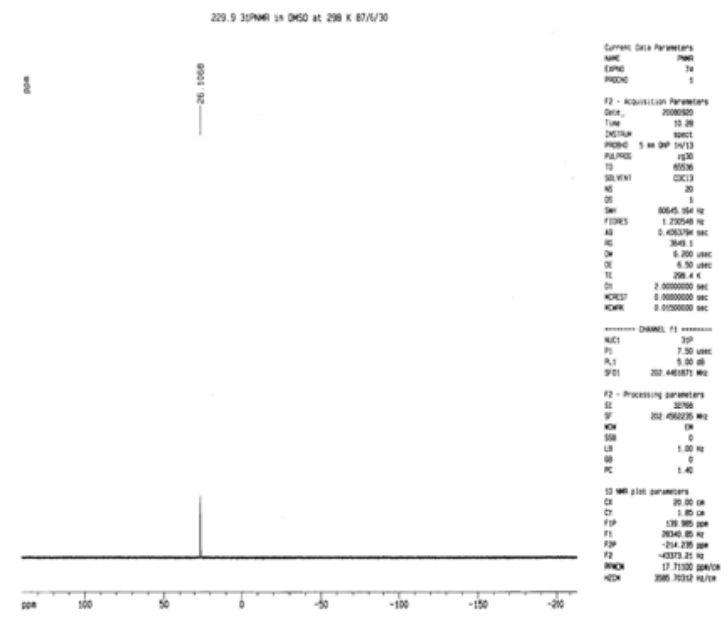

Fig. 2. 31P-NMR Spectrum of $[\mathrm{P}(\mathrm{C} 6 \mathrm{H} 5) 3 \mathrm{H}]+[\mathrm{AlCl} 3 \mathrm{I}]-$

\section{Computational Method}

We applied the DFT method to optimize and calculate molecular properties of synthesized compounds. All calculations were done by using the Gaussian 98 programs. (Fig. 3, Fig. 4) For DFT, Becke's three-parameter exchange functional was used in combination with the Lee-Yang-Parr correlation functional (B3LYP) with LANL2DZ basis set.

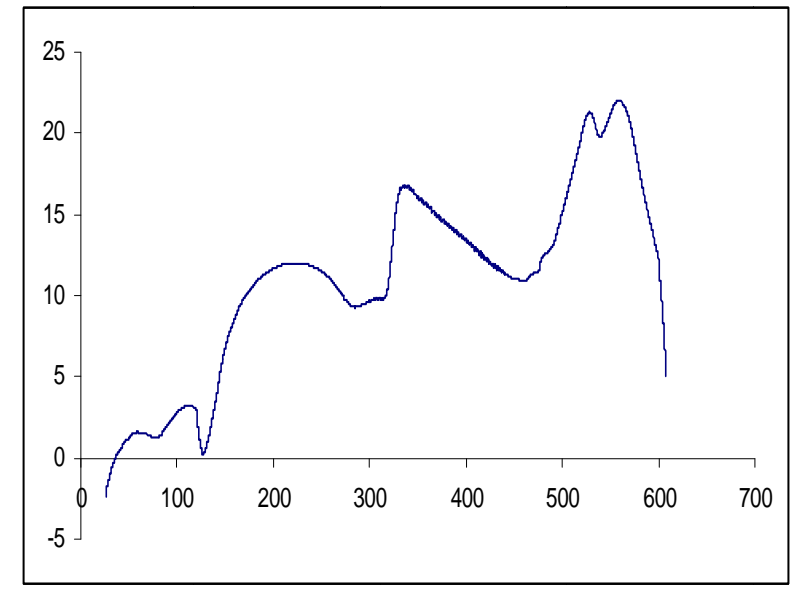

Fig. 3. DTA spectrum of $\left[\mathrm{P}_{(}\left(\mathrm{C}_{6} \mathrm{H}_{5}\right)_{3} \mathrm{H}\right]^{+}\left[\mathrm{AlCl}_{3} \mathrm{I}\right]^{-}$in acetonitrile solvent

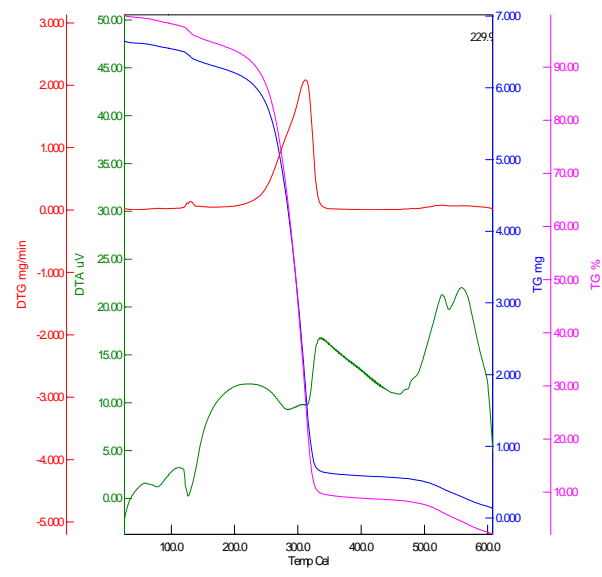

Fig. 4. TGA spectrum of $\left[\mathrm{P}\left(\mathrm{C}_{6} \mathrm{H}_{5}\right)_{3} \mathrm{H}\right]^{+}\left[\mathrm{AlCl}_{3} \mathrm{I}\right]$

Ionic molecule was used without any symmetry restriction. Calculations were done in the gas phase. After the optimization procedures, frequency calculations were done to extract vibrational mode and test the correctness of true minima. The vibrational frequencies and intensities (spectra) and the eigenvectors for the normal modes were corrected with the appropriate factor and displayed on a computer screen to identify the dominating motions (Table 1, 2, 3). 
Table 1. Experimental frequencies of $\left[\mathrm{P}\left(\mathrm{C}_{6} \mathrm{H}_{5}\right)_{3} \mathrm{H}\right]^{+}\left[\mathrm{AlCl}_{3} \mathrm{I}\right]^{-}\left(\mathrm{cm}^{-1}\right)$

\begin{tabular}{ccc}
\hline$v\left(\mathrm{~cm}^{-1}\right)$ & $\mathrm{Vibration}$ & Intensity \\
\hline 2400 & $\mathrm{P}_{\left.\mathrm{C}_{6} \mathrm{H}_{5}\right)_{3} \mathrm{H}^{+}}$ & \\
\hline 992 & $v_{\mathrm{P}-\mathrm{H} .(\mathrm{Str})}$ & $(\mathrm{s})$ \\
1474 & $v_{\mathrm{P}-\mathrm{H}}$ & $(\mathrm{m})$ \\
1656 & $v_{\mathrm{P}(\mathrm{C} 6 \mathrm{H} 5)}$ & $(\mathrm{s})$ \\
3423 & $v_{\mathrm{C} 6 \mathrm{H} 6}$ & $(\mathrm{~m} . \mathrm{w})$ \\
1427 & $v_{\mathrm{C}-\mathrm{H}(\mathrm{str})}$ & $(\mathrm{s})$ \\
539 & $v_{\mathrm{c}=\mathrm{c}}$ & $(\mathrm{w})$ \\
& $v_{=\mathrm{C}-\mathrm{H}}$ & $(\mathrm{s})$ \\
452 & {$\left[\mathrm{AlCl}_{3} \mathrm{I}\right]^{-}$} & $(\mathrm{s})$ \\
719 & $\mathrm{~B}-\mathrm{F}$ & $(\mathrm{s})$ \\
1116 & $\mathrm{~B}-\mathrm{F}$ & $(\mathrm{s})$ \\
\hline
\end{tabular}

Table 2. Comparison of the experimental and calculated data of IR spectrum

\begin{tabular}{ccc}
\hline Vibration & Experimental & Calculated \\
\hline$v_{\mathrm{P}-\mathrm{H} .(\mathrm{Str})}$ & 2400 & 2402 \\
$\boldsymbol{U}_{\mathrm{P}-\mathrm{H}}$ & 992 & 882 \\
$U_{\mathrm{P}(\mathrm{C} 6 \mathrm{H} 5)}$ & 1474 & 1474 \\
$U_{\mathrm{C} 6 \mathrm{H} 6}$ & 1656 & 1627 \\
$U_{=\mathrm{C}-\mathrm{H}(\mathrm{str})}$ & 3423 & 3250 \\
$U_{\mathrm{c}=\mathrm{c}}$ & 1427 & 1469 \\
$U_{=\mathrm{C}-\mathrm{H}}$ & 539 & 530 \\
$\mathrm{Al}-\mathrm{I}$ & 452 & 471 \\
\hline
\end{tabular}

Table 3. The Calculated Bond lengths $[\AA]$ and Bond angles $\left[{ }^{\circ}\right]$ of $\left[\mathrm{AlCl}_{3} \mathrm{I}\right]^{-}$

\begin{tabular}{cccc}
\hline Bond & Bond lengths $[\AA]$ & angles & Bond angles $\left[{ }^{\circ}\right]$ \\
\hline $\mathrm{Al}(1)-\mathrm{I}(2)$ & $2 / 648$ & $\mathrm{I}(2)-\mathrm{Al}(1)-\mathrm{Cl}(3)$ & $109 / 449$ \\
$\mathrm{Al}(1)-\mathrm{Cl}(3)$ & $2 / 255$ & $\mathrm{I}(2)-\mathrm{Al}(1)-\mathrm{Cl}(4)$ & $109 / 43$ \\
$\mathrm{Al}(1)-\mathrm{Cl}(4)$ & $2 / 255$ & $\mathrm{I}(2)-\mathrm{Al}(1)-\mathrm{Cl}(5)$ & $109 / 441$ \\
$\mathrm{Al}(1)-\mathrm{Cl}(5)$ & $2 / 255$ & $\mathrm{Cl}(3)-\mathrm{Al}(1)-\mathrm{Cl}(4)$ & $109 / 501$ \\
& & $\mathrm{Cl}(3)-\mathrm{Al}(1)-\mathrm{Cl}(5)$ & $109 / 505$ \\
\hline
\end{tabular}

\section{Results and Discussion}

The salt/Lewis acid adducts usually result in either ionic liquids or crystalline materials with low melting points. Salts containing large organic cations, such as butylpyridinium chloride or 1, 3dialkylimidazolium chloride, interact with $\mathrm{AlCl}_{3}$ to form ionically conducting liquids at room temperature. Solid $\mathrm{AlCl}_{3}$ has a melting temperature at $193{ }^{\circ} \mathrm{C}$. Upon melting, $\mathrm{AlCl}_{3}$ consists primarily of discrete $\mathrm{Al}_{2} \mathrm{Cl}_{6}$ dimers, and appears as a molecular liquid with high vapor pressure. It is well known that the melting point of $\mathrm{AlCl}_{3}$ can be lowered upon mixing with $\mathrm{RCl}$ ( $\mathrm{R}$ denotes such as an alkali metal or organic cation), which is believed to originate from the Lewis acid-base interactions of $\mathrm{AlCl}_{3}$ with $\mathrm{RCl}$ and the formation of large-sized complex anions, such as $\mathrm{AlCl}_{4}^{-}, \mathrm{Al}_{2} \mathrm{Cl}_{7}^{-}$and $\mathrm{Al}_{3} \mathrm{Cl}_{10}{ }^{-}$. From the binary phase diagram, it is found that a low-lying eutectic occurs in the 2:1 composition of $\mathrm{AlCl}_{3}-\mathrm{RCl}$. Melting temperature of the eutectic is well below that of the $\mathrm{AlCl}_{3}$, and other aluminium halides. We continue to focus on the synthesis and characterization of various ionic liquids $^{12}$. In this paper, we report the synthesis of the new ionic liquid containing (TPPTCIA) trichlorofluoroaluminate $\left[\mathrm{AlCl}_{3} \mathrm{I}\right]^{-}$anion and triphenylphosphonium $\left.\left[\mathrm{P}\left(\mathrm{C}_{6} \mathrm{H}_{5}\right)_{3} \mathrm{H}\right]^{+}\right)$cation. The Ionic liquid was synthesized through a one-step reaction. Our procedure for producing ionic liquid has some advantages. For example, there is no side product in preparing ionic liquid in our method, the reaction is quite fast and does not require any severe conditions such as high pressure or high 
temperature, and it is not sensitive to air. Reporting of the synthesis of triphenylphosphonium trichlorofluoroaluminate has been shown that aluminate compounds can be used for organic chemists. They are analog of the above aluminate compounds.

$$
\mathbf{P}\left(\mathrm{C}_{6} \mathrm{H}_{5}\right)_{3}+\mathrm{HI}+\mathrm{AlCl}_{3} \longrightarrow\left[\mathrm{P}\left(\mathrm{C}_{6} \mathrm{H}_{5}\right)_{3} \mathrm{H}\right]^{+}\left[\mathrm{AlCl}_{3} \mathrm{I}\right]^{-}
$$

After preparing the ionic liquid, it was characterized by FT-IR, ${ }^{31} \mathrm{P}-\mathrm{NMR}$, cyclic voltammetry and other popular experimental methods, and these data have already been mentioned. Moreover, Table 1 lists most important observed vibrational modes of ionic liquid in $400-4000 \mathrm{~cm}^{-1}$ range. As shown in Table 1, all reported frequencies corresponding to vibrational mode and the quantity of these frequencies agree with other similar compounds. In most of cases, frequencies in this ionic liquid are nearly the same and the difference between their frequencies is very small.

After preparing and characterizing the ionic liquid by experiments, we decided to do some calculations on these molecules. Therefore, we applied the Gaussian program and the molecule was optimized by the DFT method using B3LYP/LANL2DZ basis set.

Then, the infrared spectrum of the new ionic liquid was studied using the same method and basis set. The cations and anions are commonly assumed to be in a hypothetical gaseous free state and without any pre-assumed symmetry, but some calculations also involve better approximations to real systems. The structures of the optimized $\left[\mathrm{P}\left(\mathrm{C}_{6} \mathrm{H}_{5}\right)_{3} \mathrm{H}\right]^{+}\left[\mathrm{AlCl}_{3} \mathrm{I}\right]^{-}$in this product are depicted in (Fig. 5, Fig. 6).

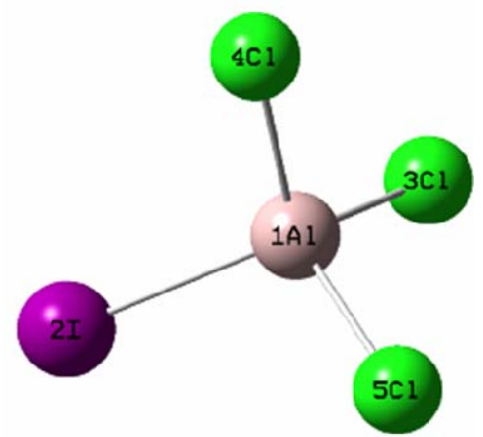

Fig. 5. Optimized structure of $\left[\mathrm{AlCl}_{3} \mathrm{I}\right]^{-}$anion

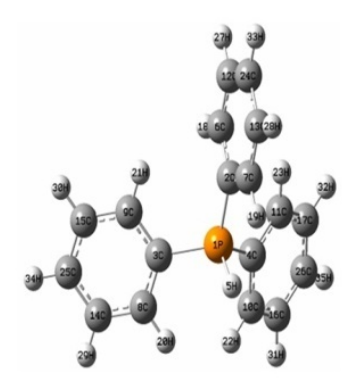

Fig. 6. Optimized structure of $\left[\mathrm{P}\left(\mathrm{C}_{6} \mathrm{H}_{5}\right)_{3} \mathrm{H}\right]^{+}$cation

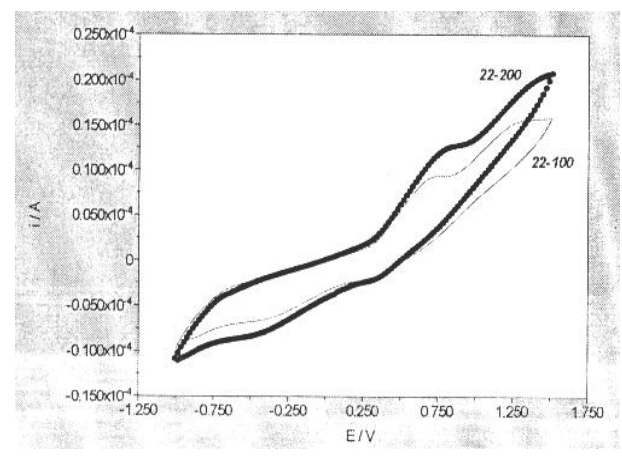

Fig. 7.Voltammogram of $\left[\mathrm{P}\left(\mathrm{C}_{6} \mathrm{H}_{5}\right)_{3} \mathrm{H}\right]^{+}\left[\mathrm{AlCl}_{3} \mathrm{I}\right]^{-}$
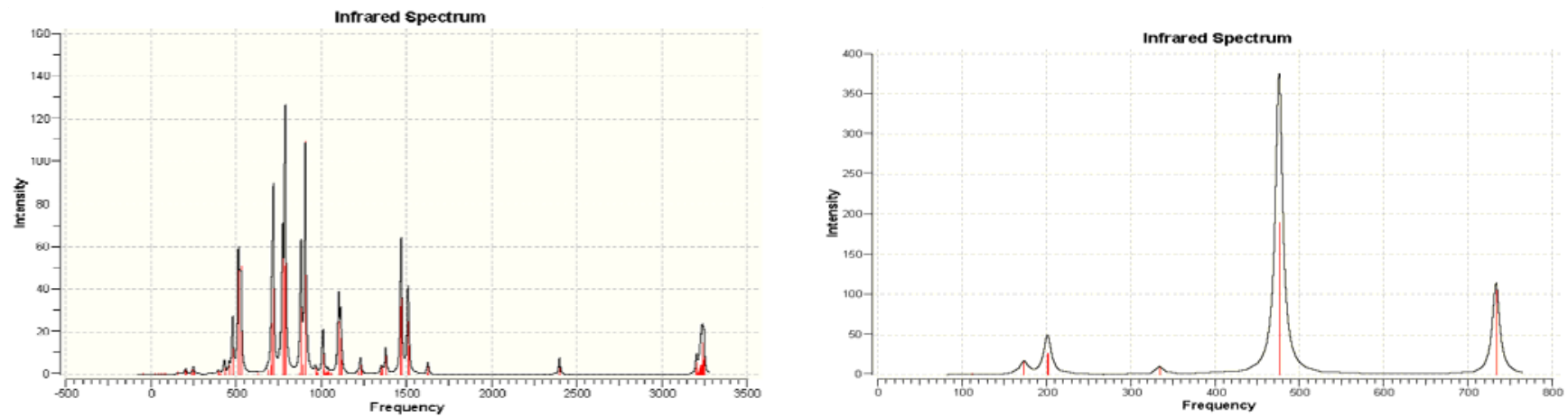

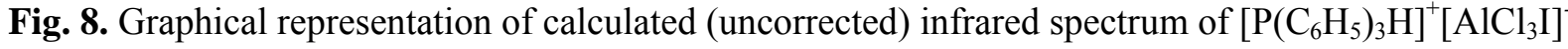

After the optimization procedures, giving geometry with a minimum energy -perhaps not a global one the vibrational frequencies and intensities and the eigenvectors for the normal modes are calculated and displayed on a computer screen, to identify the dominating motions. 
Cyclic voltammogram (CV) shows that this IL compound has reversible behavior and can be used as solvent in many reactions(Fig. 7). The calculated and experimental vibrational spectra are in good agreement. (Fig.8)

\section{Conclusions}

In this work, a novel aluminate ionic liquid with formula $\left[\mathrm{P}\left(\mathrm{C}_{6} \mathrm{H}_{5}\right)_{3} \mathrm{H}\right]^{+}\left[\mathrm{AlCl}_{3} \mathrm{I}\right]^{-}$was synthesized from the reaction of Triphenylphosphonium with acetonitrile. The ${ }^{31} \mathrm{P}-\mathrm{NMR}$ spectrum of this compound indicates a signal at $26.106 \mathrm{ppm}$. The voltammogram of this compound indicates indifferent velocities. The structure of compound has been calculated and optimized by the density functional theory (DFT) based method at B3LYP/6-311G levels of theory, using the Gaussian 98 package of programs. The comparison between theory and experiment is made. This compound was characterized by FT-IR, ${ }^{31}$ P-NMR, Cyclic Voltammogram and other techniques (Figs. 1-8).

\section{Acknowledgements}

The authors wish to express their warm thanks to Dr. Gh. Rezaei Behbahani for his valuable discussions. This work was supported by Islamic Azad University, Takestan Branch.

\section{References}

1. Linclau B., Sing A. K., and Curran D. P. (1999) Benzotrifluoride and related solvents in organic synthesis. J. Org. Chem., 64, 2835-2842.

2. Walton T. (1999) Ionic Liquid Modifies the Lower Critical Solution Temperature (LCST) of Poly( $N$-isopropylacrylamide) in Aqueous Solution. Chem. Rev., 99, 2071-2083.

3. Earle, M. J. and K. R. Seddon, (2000) Ionic liquids green solvents for the future, Pure Appl. Chem. 7, 72-78.

4. Hajipour A. R., Rajaei A. and Ruoho A. E. (2009) A mild and efficient method for preparation of azides from alcohols using acidic ionic liquid [H-NMP]HSO4, Tetrahedron Lett., 50, 708-711.

5. Wang H., Liu Y., Li Z., Zhang X., Zhang S., and Zhang Y. (2009) New aluminum-based ionic liquids: Synthesis, characterization, and theoretical study Eur. Polym. J. 45, 1535-1544.

6. Han X. and Armstrong D. W. 2007. Ionic liquids in separations, Acc. Chem. Res. 40, 10791086.

7. Anouti M., Caillon-Caravanier M., Dridi Y., Jacquemin J., Hardacre C. and Lemordant D. (2009) New aluminum-based ionic liquids: Synthesis, characterization, and theoretical study, J. Chem. Thermodyn, 41, 799-1086.

8. Mazille F., Fei Z., Kuang D., Zhao D., Zakeeruddin S. M., Grätzel M., and Dyson P. (2006) J. Influence of Ionic Liquids Bearing Functional Groups in Dye-Sensitized Solar Cells. Inorg. Chem. 45, 1585-1590.

9. Calvar N., Gonza' lez B., Dom'inguez A., and Macedo E. A. (2009) Osmotic coefficients of binary mixtures of 1-butyl-3-methylimidazolium methylsulfate and 1,3 dimethylimidazolium methylsulfate with alcohols at $\mathbf{T}=323.15 \mathrm{~K}, \mathrm{~J}$. Chem. Thermodyn., 41, 11-16.

10. Garc'1a-Miaja G., Troncoso J., Roman'I. L. (2009) Physical Properties of Binary Mixtures of ILs with Water and Ethanol, J. Chem. Thermodyn., 41, 161-166.

11. Kurnia K. A., Wilfred C. D., and Murugesan T. J. (2009) Thermophysical Properties of 1Propyronitrile-3-alkylimidazolium Bromide Ionic Liquids at Temperatures from 293.15 to $353.15 \mathrm{~K}, \mathrm{~J}$. Chem. Thermodynamics, 41, 517-521.

12. Crosthwaite J. M., Muldoon M. J., Dixon J. K., Anderson J. L., and Brennecke J. F., (2005) Phase transition and decomposition temperatures, heat capacities and viscosities of pyridinium ionic liquids. J. Chem. Thermodyn, 37, 559-568. 